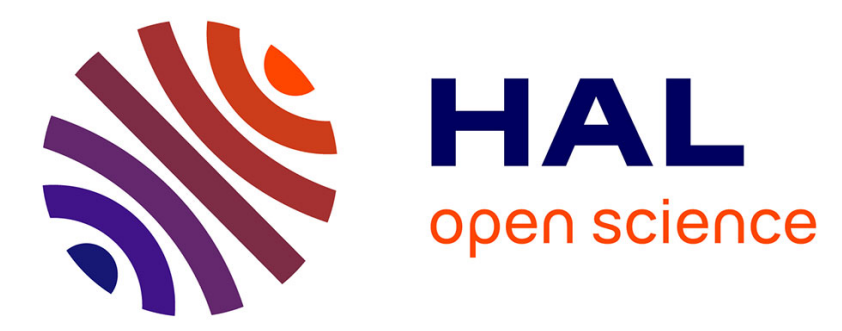

\title{
Analysis and modelling of non-equilibrium sorption of aromatic micro-pollutants on GAC with a multi-compartment dynamic model
}

Geoffroy Lesage, Mathieu Sperandio, Ligia Tiruta-Barna

\section{To cite this version:}

Geoffroy Lesage, Mathieu Sperandio, Ligia Tiruta-Barna. Analysis and modelling of non-equilibrium sorption of aromatic micro-pollutants on GAC with a multi-compartment dynamic model. Journal Chemical Engineering, 2010, 10.1016/j.cej.2010.03.045 . hal-01216044

\section{HAL Id: hal-01216044 \\ https://hal.science/hal-01216044}

Submitted on 15 Oct 2015

HAL is a multi-disciplinary open access archive for the deposit and dissemination of scientific research documents, whether they are published or not. The documents may come from teaching and research institutions in France or abroad, or from public or private research centers.
L'archive ouverte pluridisciplinaire HAL, est destinée au dépôt et à la diffusion de documents scientifiques de niveau recherche, publiés ou non, émanant des établissements d'enseignement et de recherche français ou étrangers, des laboratoires publics ou privés. 


\section{Accepted Manuscript}

Title: Analysis and modelling of non-equilibrium sorption of aromatic micro-pollutants on GAC with a multi-compartment dynamic model

Authors: Geoffroy Lesage, Mathieu Sperandio, Ligia Tiruta-Barna

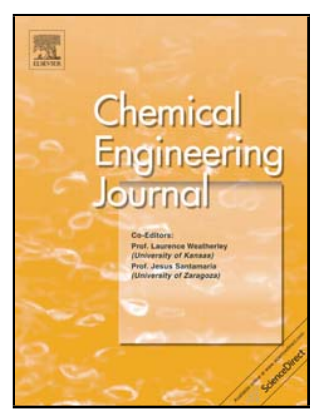

PII: S1385-8947(10)00264-0

DOI:

Reference: doi:10.1016/j.cej.2010.03.045

To appear in: $\quad$ Chemical Engineering Journal

Received date: $\quad 18-9-2009$

Revised date: $\quad 18-3-2010$

Accepted date: $\quad$ 19-3-2010

Please cite this article as: G. Lesage, M. Sperandio, L. Tiruta-Barna, Analysis and modelling of non-equilibrium sorption of aromatic micro-pollutants on GAC with a multi-compartment dynamic model, Chemical Engineering Journal (2008), doi:10.1016/j.cej.2010.03.045

This is a PDF file of an unedited manuscript that has been accepted for publication. As a service to our customers we are providing this early version of the manuscript. The manuscript will undergo copyediting, typesetting, and review of the resulting proof before it is published in its final form. Please note that during the production process errors may be discovered which could affect the content, and all legal disclaimers that apply to the journal pertain. 


\title{
Analysis and modelling of non-equilibrium sorption of
}

\author{
aromatic micro-pollutants on GAC with a multi-
} compartment dynamic model

.

5

\section{Abstract}

The optimisation of granular activated carbon (GAC) processes for industrial wastewater treatment requires the development of dynamic model that considers adsorption in multi-compartment porous media. In this work, the adsorption of toluene and naphthalene on GAC is investigated. Sorption equilibrium and kinetic experiments were performed at laboratory scale using low contaminant concentrations. The experimental conditions were chosen so as to simultaneously explore the different ranges of concentrations typically encountered in industrial wastewaters. The sorption behaviour was then explained through modelling taking into account the main equilibrium and transport phenomena and three adsorption compartments: the GAC particle surface, the macro- and meso-pores, and the micropores. The pore diffusion and solid diffusion were both considered to be coupled with a linear adsorption isotherm. With one set of four parameters adjusted for an adsorbent/contaminant pair, the model satisfactorily describes the nonequilibrium adsorption/desorption processes in different operating conditions and initial conditions.

Keywords: Kinetics, Mass transfer, Diffusion, PAH, Toluene.

*Corresponding author. Tel: +33(0)5 615597 88; Fax: +33 (0)5 61559760

E-mail address: ligia.barna@insa-toulouse.fr 


\section{Introduction}

26

27 Because of industrial and urban development, many hazardous organic substances and micro-pollutants are discharged into the environment via wastewaters (Williams, 1990; Douben, 2003). Removing chemical contaminants from wastewaters continues to be a central problem in environmental remediation and severe discharge

31 constraints are now imposed by legislation for a number of chemicals (Water

32 Framework Directive 2000) like monoaromatic and polyaromatic hydrocarbons.

33 Adsorption is a well established technique for the removal of low concentrations of organic pollutants from industrial wastewater. Among the many adsorbents available, activated carbon is effective in removing a large variety of organic components (Seidel et al., 1985). Treatment options may range from activated carbons that differ in pore structure and surface chemistry to the control of one or more chemical compounds and mixtures. Granular Activated Carbon (GAC) has been shown to be efficient for the removal of organic micropollutants including aromatic hydrocarbons,

40 halogenated hydrocarbons, pesticides, polychlorobiphenyl and surfactants

41 (Zimmerman et al., 2004). The optimisation of GAC processes for industrial wastewater treatment demands a good knowledge of the adsorption and desorption dynamics. When GAC is operated in a completely mixed reactor (ref) fed with wastewater, it can be subjected to micropollutant concentrations that vary with time, leading to non-equilibrium in the system. Few studies have reported the analysis of this dynamics, which depends on mechanisms of internal diffusion into GAC in different compartments of the granular medium: surface, macro-porosity and microporosity. 
50 The present work focuses on two substances typically found in industrial

51 wastewaters: toluene and naphthalene. Toluene and naphthalene have been

52 characterized as potential human carcinogens and their maximum permissible

53 concentrations in drinking water range from 4.6 to $0.3 \mu \mathrm{g} \mathrm{L}^{-1}$ among different countries

54 (WHO, 2006). Toluene is a very popular solvent, used in the electronics, chemical 55 and printing industries. Polycyclic aromatic hydrocarbons (PAH) are produced by 56 human activity, chiefly in the pyrolysis and combustion processes employed in 57 industry, transport and heating (Bouchez et al., 1996). These substances cause their genotoxicity to living organisms. The chemical properties of toluene and naphthalene differ by their volatility and hydrophobicity: toluene is a highly volatile 61 organic compound (VOC) while naphthalene is characterized by lower water 62 solubility and high octanol-water partioning coefficients (Log $\left.\mathrm{K}_{\mathrm{ow}}\right)$. Naphthalene is one 63 of the most soluble of the PAH and therefore represents the worst case for PAH mobility. In many studies, naphthalene is used as a model chemical for hydrophobic organics. Since GAC is a heterogeneous granular medium with particle sizes ranging from 0.5 to $10 \mathrm{~mm}$, a bimodal pore distribution (macro and microporous) and a high specific surface area $\left(500-2000 \mathrm{~m}^{2} \mathrm{~g}^{-1}\right)$ (Cheremisinoff and Cheremisinoff, 1993), it is particularly suitable for the efficient sorption of high molecular weight organic molecules with lipophilic properties, as is the case with PAH (Jonker and Koelmans, 2002). Ania et al. (2007) found that the adsorption of naphthalene depended strongly on the pore size distribution of the adsorbent, particularly narrow microporosity.

72 Although the microporous surface constitutes a major fraction of the specific surface 73 area, adsorption of organic micropollutants also occurs on the external surface of 74 particles and macro-pore walls. Whereas the experimental characterisation of 
adsorption of GAC is frequent in the literature (Seredych et al., 2005; Ania et al., 2007; Valderrama et al., 2007; 2008a; 2008b; Cabal et al., 2009b), dynamic models that consider adsorption in multi-compartment porous media are rare. The sorption of organic micropollutants onto natural and synthetic sorbents has been described as a complex process in which the properties of the sorbate and the solvent play a critical role. The sorption process occurs within the boundary layer around the sorbent and proceeds in the liquid-filled pores or along the walls of the pores of the sorbent. As the classical modelling approaches point out, the adsorption process is composed of several steps:

- Diffusion of the pollutant from bulk liquid through the thin film of liquid surrounding the GAC particle (external transfer).

- Pollutant adsorption on the particle's external surface.

- Diffusion inside the pores (internal transfer) by two main mechanisms: pore diffusion (in large pores) and/or surface diffusion (in all pores, particularly in narrow, molecular-size-like pores).

- Adsorption on the pore walls.

Within a perfectly stirred reactor at constant temperature, adsorption rate is controlled by extra- or intra-particular diffusion steps. The relative importance of these steps depends on the adsorbent structure (particle diameter, pore length and diameter), solute properties (solute diffusivities) and hydrodynamic conditions. The design of a full-scale process requires knowledge not only of the equilibrium state but also of the dynamics of the solute adsorption/desorption processes, which depend strongly on the different steps described above. 
In most studies, the adsorption rate of organic compounds from aqueous solutions is modelled by using several simplistic mathematical expressions that include the pseudo-first order (Lagergren, 1898), pseudo-second order (Vinod and Anirudhan, 2003; Wu et al., 2009), the intraparticle diffusion model (Weber, 1963; Cabal et al., 2009a) and the Elovich model (Chien and Clayton, 1980). Although these kinetic equations have been frequently employed to interpret adsorption data obtained under non-equilibrium conditions, their theoretical origins still remain unknown (Liu and Shen, 2008). The specific parameters contained in these equations can be determined only by fitting on experimental data and are dependent on the operating conditions, e.g. the initial sorbate concentrations. Wu et al (2009) observed that, for the same sorbate/sorbent pair, the performance of a given kinetic model depended on the particle sizes. Another common aspect of most studies on PAH adsorption is that the solutions used were relatively concentrated (with respect to the PAH solubility) and prepared using a co-solvent (alcohol), in a narrow range of concentration values.

To describe the equilibrium adsorption, the most commonly used models are the Langmuir and Freundlich models (Cornelissen et al., 2005; Pikaar et al., 2006). Pikaar et al. (2006) have performed a statistical analysis on isotherm models to fit sorption data for the sorption of organic compounds to activated carbon and found that the dual Langmuir equation is, in general, preferable to the single and triple Langmuir equations, the Freundlich equation, a Polanyi-Dubinin-Manes equation, or the Toth equation. Naphthalene adsorption equilibrium in aqueous solution has been studied through the Langmuir-Freundlich single solute isotherm (Derylo-Marczewska, 1984; Ania et al., 2007) 
123 However, few works have developed physical deterministic models for the

124 explanation of the adsorption kinetics of toluene and naphthalene on activated

125 carbon. Some studies have been conducted on simulation and prediction of pilot 126 plant and full-scale adsorber data, e.g. Crittenden et al. (1987), who used a

127 homogeneous solid diffusion model (HDSM) of GAC adsorption of dichloroethylene

128 in a contaminated groundwater matrix. Valderrama et al. (2008a), have studied PAH

129 removal through GAC adsorption and found that the rate-determining step of $\mathrm{PAH}$

130 extraction is the sorbent-phase diffusion. They used two non-equilibrium adsorption

131 models: the Homogeneous Particle Diffusion Model (HPDM) and the Shell

132 Progressive Model (SPM) and have determined PAH effective particle diffusion

133 coefficients $\left(D_{\text {eff }}\right)$ in the range $1.1 * 10^{-13}-6.0 * 10^{-14} \mathrm{~m}^{2} \cdot \mathrm{s}^{-1}$. Though many papers

134 dealing with adsorption of organic substances from aqueous solutions have been

135 published (Seredych et al., 2005; Ania et al., 2007; Valderrama et al., 2007; 2008a;

136 2008b; Cabal et al., 2009b); the rate and the mechanisms of the adsorption process

137 itself remain unclear. Therefore, it would be appropriate to evaluate a model capable

138 of predicting the equilibrium and kinetic sorption performance of GAC for aqueous

139 trace organic molecules based on fundamental sorbent and sorbate properties.

141 Therefore, in this paper, aromatics with one and two rings (toluene and naphthalene)

142 are evaluated in a set of sorption and desorption tests on GAC in completely stirred

143 cells, with the following objectives:

144 - to determine the adsorption behaviour, i.e. kinetic and equilibrium parameters, on 145 an extended time scale (short term to long term), in extreme concentration conditions 146 (low to high) expected to be found in ground and industrial wastewater, i.e. typically 147 in the range of $0.2-200 \mathrm{~g} \mathrm{~m}^{-3}$, 
148 - to quantify the main phenomena through a mechanistic modelling approach,

149 - and to build a model containing a reduced number of adjusted parameters

150 (parameters with a physical meaning) which simulates the adsorption/desorption

151 behaviour in different operating conditions. This model should be easy to handle and

152 resolve and should also allow for its integration in larger models of more complex

153 systems (for example adsorber modelling, or coupling with other bio-physicochemical

154 phenomena).

155

2. Materials and experimental methods

157

Adsorbates and adsorbents

159 Toluene and naphthalene were supplied by Sigma Aldrich. Toluene from the BTEX

160 group solvents was chosen as a typical mono-aromatic hydrocarbon, naphthalene

161 was chosen as a model compound for a light molecule of the group of polyaromatic

162 hydrocarbons. All the above chemicals were more than $99 \%$ pure. Organic stock

163 solutions were prepared in ultrapure water in a concentration range of approximately

1640.2 to $200 \mathrm{~g} \mathrm{~m}^{-3}$.

165

166 The Granular Activated Carbon (GAC) employed as the adsorbent was supplied by

167 Pica and had the characteristics presented in Table 2. The GAC was obtained from

168 coconut which was thermally activated and had a mean granulometry of $0.5-0.8 \mathrm{~mm}$.

169 The BET (Brunauer-Emmett-Teller) surface area $\left(1707 \mathrm{~m}^{2} \mathrm{~g}^{-1}\right.$ ) was obtained from $\mathrm{N}_{2}$

170 adsorption isotherms at $77 \mathrm{~K}$ on an ASAP2010 micrometrics apparatus. The

171 isotherms were used to calculate the total pore volume, specific surface area and

172 pore size distributions with t-plot and HK (Horwath-Kawazoe) modelling. Prior to 
173 addition to the vials, the GAC was rinsed three times with ultra-pure water to remove

174 dissolved contaminants and fine particles, which could have affected the adsorption

175 capacity of the activated carbon (Summers and Roberts, 1988; Srivastava and Tyagi,

176 1995). The GAC was then dried at $105^{\circ} \mathrm{C}$ for $24 \mathrm{~h}$ prior to storage in a dessicator until

177 use (Cooney and $\mathrm{Xi}, 1994)$. It is generally accepted that activated carbon has a

178 bimodal pore size distribution and contains pores ranging from several microns to a

179 few angstroms. According to the classification by the International Union of Pure and

180 Analytical Chemistry (IUPAC), there are three types of pores: micropores having

181 dimensions less than $2 \mathrm{~nm}$, macropores larger than $500 \mathrm{~nm}$, and mesopores lying

182 between these two limits.

183

184 Adsorption of pollutants on GAC

185 Adsorption measurements of toluene and naphthalene from aqueous solutions on

186 carbon adsorbents were performed at $25^{\circ} \mathrm{C}$ in a stirred batch system, which

187 consisted of $120 \mathrm{~mL}$ amber glass vials filled without headspace and closed with

188 Teflon-coated septa. Experiments were conducted in laboratory ultrapure water (tap

189 water treated by ion exchange and UV). All points were obtained in duplicate or

190 triplicate. A control sample without GAC was identically prepared for each

191 experiment. The different aqueous solutions of pollutants without solid were first

192 stirred on a rotary stirrer for $72 \mathrm{~h}$. Measurement by GCMS determined the real initial

193 concentration of the solution before the adsorption experiment, taking into account

194 the artefacts associated with the adsorption of pollutants on the different components

195 of the reactor (Huang et al., 1988). The GAC was then weighed with an accuracy of

$196+/-0.001 \mathrm{~g}$ and added into the vials. Tightly closed, the vials were shaken for $2-168 \mathrm{~h}$

197 for the kinetic study. This revealed that the concentration values stabilised 
198 (suggesting that equilibrium was reached) in $15 \mathrm{~h}$ for NAP and $24 \mathrm{~h}$ for Toluene (see

199 below). After stirring, the tubes were centrifuged for $20 \mathrm{~min}$ at $2500 \mathrm{rpm}$. The residual

200 pollutant concentration of the supernatant was then determined by GCMS analysis

201 and the adsorbed amount was calculated from the difference between initial and

202 residual concentrations. The adsorbed quantity $Q_{\exp }$ is given by the following 203 equation:

$204 \mathrm{Q}_{\exp }=\left(\mathrm{C}_{0, \exp }-\mathrm{C}_{\exp }\right) \cdot \frac{\mathrm{V}}{\mathrm{S}}$

205 Where $\mathrm{C}_{0, \exp }$ and $\mathrm{C}_{\exp }$ are the initial and equilibrium concentrations respectively $206\left(\mathrm{~g} \mathrm{~m}^{-3}\right), \mathrm{V}$ the volume of solution $\left(\mathrm{m}^{3}\right)$ and $\mathrm{S}$ the mass of solid $(\mathrm{g})$.

\section{Analytical procedures}

209 Pollutant concentrations were determined using a gas chromatograph (Varian 3900),

210 equipped with a mass spectrometer detector (Saturn 2100T) using helium (99.999\%

211 purity) as carrier gas coupled with an automatic headspace sampler (Quma HSS40).

212 Separation was accomplished using a $30 \mathrm{~m}^{\star} 0.25 \mathrm{~mm}^{\star} 0.25 \mu \mathrm{m}$ column (fused silica

213 VARIAN, type VF-5MS (5\% phenyl 95\% dimethylpolysiloxane)). The water samples

$214(10 \mathrm{~mL})$ were transferred to $20 \mathrm{~mL}$ glass vials with Teflon-coated septa and aluminium

215 seals. The samples were equilibrated for $30 \mathrm{~min}$ at $80^{\circ} \mathrm{C}$ and an aliquot of $1 \mathrm{~mL}$ of the

216 headspace gas was injected into the gas chromatograph. The detection limit was

$2171 \mu \mathrm{g} \mathrm{L}^{-1}$. The accuracy for measurements of split samples containing a concentration

218 of $1.5 \mu \mathrm{g} \mathrm{L}^{-1}$ was $+/-0.1 \mu \mathrm{g} \mathrm{L}^{-1}$. All vials were first washed and dried in a $500^{\circ} \mathrm{C}$ oven to 219 remove all traces of organics. 
SEM analysis

224 A JEOL 5410LV Scanning Electron Microscope was used to observe the surface

225 morphology of GAC (Figure 1.a). Prior to analysis, samples were dried in a vacuum oven at room temperature and then gold coated.

\section{Modelling}

The model applied was based on the four-step conceptual model:

- External diffusion of the pollutant through the thin liquid film surrounding the GAC particle.

233 - Pollutant adsorption on the particle's external surface.

234 - Internal diffusion by two main mechanisms: pore diffusion (in large pores) and surface diffusion. - Adsorption on the pore walls.

238 And on the following supplementary assumptions:

239 - The adsorbent particles are spherical (particle diameter is given by the 240 arithmetic mean value of the mesh size) (Figure 1.b).

241 - Pores of different sizes are parallel, i.e. transfer between different types of 242 pore is not considered.

243 - Two main diffusion mechanisms should be taken into account. For large pores 244 (macro- and meso-pores) only the pore diffusion is considered because it is 245 several orders of magnitude faster than the solid diffusion. As the two 246 mechanisms occur in parallel, the slower one can be ignored. For the narrow 247 (micro) pores, only solid diffusion is considered. 
252 Consequently, the model contains three adsorption compartments: the external

- Two pore categories are considered: 1) macropores (the ratio of volume to surface area is very small for the macropores of the adsorbent studied); 2) micropores (pore size $<2 \mathrm{~nm}$ ).

surface, the macro/meso pores and the micropore surfaces.

The external transfer is characterised by:

- the specific surface area $a_{s}\left(\mathrm{~m}^{2} \mathrm{~m}^{-3}\right)$ corresponding to the geometric surface area of the particles of radius $R(m)$,

- $\quad$ the external mass transfer coefficient $\mathrm{k}_{\mathrm{ext}}\left(\mathrm{m} \mathrm{s}^{-1}\right)$ associated with this surface.

According to the principles stated above, the dynamic adsorption model was composed of the following equations.

-Macro- and meso-pore diffusion and adsorption (in spherical coordinates):

$\varepsilon_{\mathrm{p}} \frac{\partial \mathrm{C}_{\mathrm{p}}}{\partial \mathrm{t}}+\sigma_{\mathrm{p}} \rho \frac{\partial \mathrm{Q}_{\mathrm{p}}}{\partial \mathrm{t}}=\frac{1}{\mathrm{r}^{2}} \frac{\partial}{\partial \mathrm{r}}\left(\mathrm{r}^{2} \mathrm{D}_{\mathrm{e}} \frac{\partial \mathrm{C}_{\mathrm{p}}}{\partial \mathrm{r}}\right)$

with the boundary conditions:

$$
-r=0, \frac{\partial C_{p}}{\partial r}=0
$$

$$
-\quad r=R, D_{e} \frac{\partial C_{p}}{\partial r}=k_{e x t}\left(C-\left.C_{p}\right|_{R}\right) \equiv \text { flux }_{p}
$$

$C$ is the bulk concentration $\left(\mathrm{g} \mathrm{m}^{-3}\right)$. For the meso- and macro-pore compartment: $C_{p}$ and $Q_{p}$ are the pore concentration $\left(\mathrm{g} \mathrm{m}^{-3}\right)$ and adsorbed quantity $\left(\mathrm{g} \mathrm{m}^{-2}\right)$ at local coordinates of time $t(s)$ and space $r(m), D_{e}$ is the effective diffusion coefficient $\left(m^{2} s^{-}\right.$ $\left.{ }^{1}\right), \varepsilon_{p}$ is the porosity, $\rho\left(\mathrm{g} \mathrm{m}^{-3}\right)$ is the particle density, $\sigma_{\mathrm{p}}$ is the specific surface area $\left(\mathrm{m}^{2} \mathrm{~g}^{-1}\right)$, flux $\left(\mathrm{g} \mathrm{m}^{-2} \mathrm{~s}^{-1}\right)$ is the flux exchanged between the pore compartment and the bulk liquid phase. 
271 -Micropores (pore width comparable with the molecular size) solid diffusion

$272 \quad \frac{\partial \mathrm{Q}_{\mathrm{mp}}}{\partial \mathrm{t}}=\frac{1}{\mathrm{r}^{2}} \frac{\partial}{\partial \mathrm{r}}\left(\mathrm{r}^{2} \mathrm{D}_{\mathrm{s}} \frac{\partial \mathrm{Q}_{\mathrm{mp}}}{\partial \mathrm{r}}\right)$

273 with the boundary conditions:

$274 \quad-\quad r=0, \frac{\partial Q_{m p}}{\partial r}=0$

$275 \quad-\quad r=R, D_{s} \frac{\partial Q_{m p}}{\partial r}=\frac{k_{e x t}}{\sigma_{m p} \rho}\left(C-\left.C_{m p}^{e}\right|_{R}\right)$

276 The flux exchanged between the micropores and the bulk liquid is:

277

$$
\mathrm{k}_{\mathrm{ext}}\left(\mathrm{C}-\left.\mathrm{C}_{\mathrm{mp}}^{\mathrm{e}}\right|_{\mathrm{R}}\right) \equiv \text { flux }_{\mathrm{mp}}
$$

278 For the micropore compartment (subscript $\mathrm{mp}$ ): $\mathrm{Q}_{\mathrm{mp}}$ is the locally adsorbed quantity

$279\left(\mathrm{~g} \mathrm{~m}^{-2}\right),\left.\mathrm{C}_{\mathrm{mp}}^{\mathrm{e}}\right|_{\mathrm{R}}$ is the concentration at $\mathrm{R}$ in equilibrium with $Q_{m p}$ at $R, D_{s}$ is the 280 surface diffusion coefficient $\left(\mathrm{m}^{2} \mathrm{~s}^{-1}\right), \sigma_{\mathrm{mp}}$ is the specific surface area $\left(\mathrm{m}^{2} \mathrm{~g}^{-1}\right)$, flux $\mathrm{mp}$ $281\left(\mathrm{~g} \mathrm{~m}^{-2} \mathrm{~s}^{-1}\right)$ is the flux exchanged between the micropore compartment and the bulk 282 liquid.

283 -External transfer and surface adsorption:

$284 \frac{\mathrm{dQ}_{\text {ext }}}{\mathrm{dt}}=\mathrm{k}_{\text {ext }}\left(\mathrm{C}-\mathrm{C}_{\mathrm{ext}}^{\mathrm{e}}\right) \frac{\mathrm{a}_{\mathrm{S}}}{\sigma_{\text {ext }} \rho}$

$\mathrm{k}_{\mathrm{ext}}\left(\mathrm{C}-\mathrm{C}_{\mathrm{ext}}^{\mathrm{e}}\right) \equiv$ flux $_{\mathrm{ext}}$

$286 Q_{\text {ext }}$ is the quantity adsorbed $\left(\mathrm{g} \mathrm{m}^{-2}\right)$ on the external surface of particles (variable only

287 in time), $\mathrm{C}_{\mathrm{ext}}^{\mathrm{e}}$ is the liquid film concentration near the particle side in equilibrium with

$288 Q_{\text {ext }}, \sigma_{\text {ext }}$ is the external specific area available for adsorption $\left(\mathrm{m}^{2} \mathrm{~g}^{-1}\right)$, flux $\mathrm{ext}\left(\mathrm{g} \mathrm{m}^{-2} \mathrm{~s}^{-1}\right)$

289 is the flux exchanged between the particle external surface and the bulk liquid.

290 -Bulk liquid mass balance: 
291 The variation of pollutant concentration in the bulk liquid is due to the pollutant fluxes

292 transferred towards the particle's external surface and to the pores.

$293 \varepsilon \varepsilon \frac{d C}{d t}=-\left(a_{s}\right.$ flux $_{\text {ext }}+a_{s}$ flux $_{p}+a_{s}$ flux $\left._{m p}\right)$

294 The adsorption isotherm is taken to be linear for the concentration range limited by

295 the weak solubility. Saturation was not observed in any set of experiments. The

296 adsorption constant $\mathrm{K}_{\mathrm{e}}$ is expressed in $\mathrm{m}^{3} \mathrm{~m}^{-2}$ and represents a partition coefficient

297 between the liquid and the surface. Adsorption is also considered to be rapid and

298 reversible while a physical interaction mechanism is involved; the local equilibrium

299 assumption is adopted in the model. The same linear adsorption equation was

300 applied for all compartments, for example in the macro and mesopores:

$301 \quad \mathrm{Q}_{\mathrm{p}}=\mathrm{K}_{\mathrm{e}} \mathrm{C}_{\mathrm{p}}$

$302 \frac{\mathrm{dQ}_{\mathrm{p}}}{\mathrm{dt}}=\mathrm{K}_{\mathrm{e}} \frac{\mathrm{dC}_{\mathrm{p}}}{\mathrm{dt}}$

303

304 The disadvantage of the present model with respect to its resolution and practical

305 applications is the presence of two-dimensional variables $C_{p}, Q_{p}$ and $Q_{m p}$ (time and

306 radius). Previous modelling studies of adsorption systems (Do and Rice, 1986; Goto

307 et al., 1990) revealed the possibility of transforming the models based on partial

308 differential equations (time and space) into simple differential equations (time) in the case of linear absorption, for both pore diffusion and solid diffusion mechanisms.

311 In this simplified approach, mean concentrations are used instead of the radially

312 varying concentrations. One of the consequences is the possibility of using the "linear

313 driving force" model (Gleuckauf, 1947) associated with a global mass transfer

314 coefficient $\mathrm{k}_{0}$ between the bulk liquid and the pores: 
$315 \frac{1}{\mathrm{k}_{0, \mathrm{p}}}=\frac{1}{\mathrm{k}_{\mathrm{ext}}}+\frac{\mathrm{R}}{5 \mathrm{D}_{\mathrm{e}}}$

$316 \frac{1}{\mathrm{k}_{0, \mathrm{mp}}}=\frac{1}{\mathrm{k}_{\mathrm{ext}}}+\frac{\mathrm{R}}{5 \mathrm{D}_{\mathrm{s}}}$

317 Where $k_{o, p}$ and $k_{o, m p}$ are the overall transfer coefficient for macro- and meso-pores

318 and for micropores respectively $\left(\mathrm{m} \mathrm{s}^{-1}\right)$.

319 With these assumptions, the final form of the model becomes:

$320 \quad \varepsilon_{\mathrm{p}} \frac{\mathrm{d} \overline{\mathrm{C}}_{\mathrm{p}}}{\mathrm{dt}}+\sigma_{\mathrm{p}} \rho \frac{\mathrm{d} \overline{\mathrm{Q}}_{\mathrm{p}}}{\mathrm{dt}}=\mathrm{a}_{\mathrm{s}} \mathrm{k}_{\mathrm{o}, \mathrm{p}}\left(\mathrm{C}-\overline{\mathrm{C}_{\mathrm{p}}}\right)$

$321 \quad \frac{\mathrm{d} \overline{\mathrm{Q}}_{\mathrm{p}}}{\mathrm{dt}}=\mathrm{K}_{\mathrm{e}} \frac{\mathrm{d} \overline{\mathrm{C}}_{\mathrm{p}}}{\mathrm{dt}}$

$322 \frac{\mathrm{d} \overline{\mathrm{Q}}_{\mathrm{mp}}}{\mathrm{dt}}=\frac{\mathrm{a}_{\mathrm{s}} \mathrm{k}_{\mathrm{o}, \mathrm{mp}}}{\sigma_{\mathrm{mp}} \rho}\left(\mathrm{C}-\overline{\mathrm{C}_{\mathrm{mp}}^{\mathrm{e}}}\right)$

$323 \quad \overline{\mathrm{C}}_{\mathrm{mp}}^{\mathrm{e}}=\frac{\overline{\mathrm{Q}}_{\mathrm{mp}}}{\mathrm{K}_{\mathrm{e}}}$

$324 \quad \frac{\mathrm{dQ}_{\mathrm{ext}}}{\mathrm{dt}}=\frac{\mathrm{a}_{\mathrm{s}} \mathrm{k}_{\mathrm{ext}}}{\sigma_{\mathrm{ext}} \rho}\left(\mathrm{C}-\mathrm{C}_{\mathrm{ext}}^{\mathrm{e}}\right)$

$325 \quad \mathrm{C}_{\mathrm{ext}}^{\mathrm{e}}=\frac{\mathrm{Q}_{\mathrm{ext}}}{\mathrm{K}_{\mathrm{e}}}$

$326 \frac{\mathrm{dC}}{\mathrm{dt}}=\frac{\varepsilon-1}{\varepsilon}\left[\mathrm{a}_{\mathrm{s}} \mathrm{k}_{\mathrm{o}, \mathrm{p}}\left(\mathrm{C}-\overline{\mathrm{C}_{\mathrm{p}}}\right)+\mathrm{a}_{\mathrm{s}} \mathrm{k}_{\mathrm{o}, \mathrm{mp}}\left(\mathrm{C}-\overline{\mathrm{C}_{\mathrm{mp}}^{\mathrm{e}}}\right)+\mathrm{a}_{\mathrm{s}} \mathrm{k}_{\mathrm{ext}}\left(\mathrm{C}-\mathrm{C}_{\mathrm{ext}}^{\mathrm{e}}\right)\right]$

328 The overscored concentrations $\overline{\mathrm{C}}$ and $\overline{\mathrm{Q}}$ represent concentrations averaged over the 329 particle with respect to the radial coordinate and hence depend only on the time 330 coordinate. The total adsorbed quantity $\mathrm{Q}\left(\mathrm{g} \mathrm{g} \mathrm{g}^{-1}\right)$ results from a mass balance 331 calculation over the different particle compartments: 


$$
\mathrm{Q}=\sigma_{\mathrm{p}} \overline{\mathrm{Q}}_{\mathrm{p}}+\sigma_{\mathrm{mp}} \overline{\mathrm{Q}}_{\mathrm{mp}}+\sigma_{\mathrm{ext}} \mathrm{Q}_{\mathrm{ext}}+\varepsilon_{\mathrm{p}} \frac{\mathrm{S}}{\rho} \overline{\mathrm{C}}_{\mathrm{p}}
$$

334 The model contains a set of parameters available from experimental data and 335 measurements, listed with their values in Table 2.

336 The system of equations (Eq.16-22) was numerically resolved in MATLAB®. A multi-

337 parameter optimisation procedure was used for fitting the four specific parameters,

338 i.e. $\mathrm{K}_{\mathrm{e}}, \mathrm{k}_{\mathrm{o}, \mathrm{p}}, \mathrm{k}_{\mathrm{o}, \mathrm{mp}}$ and $\mathrm{k}_{\mathrm{ext}}$, based on the objective function OF to be minimized:

$$
\mathrm{OF}=\frac{1}{\mathrm{n}} \sum_{1}^{\mathrm{n}}\left(\frac{\left|\mathrm{C}_{\text {sim }}-\mathrm{C}_{\exp }\right|}{\mathrm{C}_{\exp }}\right)^{2}
$$

340 where $\mathrm{n}$ is the number of experimental data, and $\mathrm{C}_{\operatorname{sim}}$ and $\mathrm{C}_{\exp }$ are the simulated and

341 measured bulk concentrations respectively.

342 The model should represent the adsorption process for any initial conditions

343 (adsorption and desorption processes) and contact durations. The complete sets of

344 adsorption experimental data (i.e. kinetics and pseudo-isotherm results) were used

345 for the fitting procedure: about 100 and 70 points for toluene and naphthalene

346 respectively. Desorption experimental data were then used for model validation.

348 The model presents the advantages of considering different kinds of pores with their

349 transport specificities and using mean concentrations of a given compartment, thus 350 simplifying the numerical resolution. The principal weakness is that the porous 351 system is considered to be built up only of parallel pores while, in reality, connections 352 also exist between pores. Ding et al. (2002) used a model based on two types of 353 interconnected porosity. This model is more realistic but its numerical resolution is 354 not trivial (partial differential equations of second order with complex boundary 
conditions). Its use for common applications and extensions for adsorber design

356 could be very difficult.

357

358

359

360

361

362

363

364

365

366

367

368

369

370

371

372

373

374

375

376

377

378

\section{Results and discussion}

As explained previously, two kinds of experiments were performed: (1) a kinetic study in which the evolution of the eluate concentration was measured versus time; (2) a pseudo-isotherm study in which the evolution of the eluate concentration was measured when the ratio GAC/liquid (i.e. S/L) varied, for a given initial concentration $\mathrm{C}_{0, \exp }$ and a given constant contact time. Examples of experimental results are given in Figure 2 for toluene and naphthalene: kinetics obtained for different initial concentration values $\left(\mathrm{C}_{0, \exp }\right)$ and isotherms obtained for different $\mathrm{C}_{0, \exp }$ and contact times.

The experimental results show the dependence of the adsorption kinetics and isotherms on the initial concentration. The explanation of the experimental results is not obvious especially for the atypical behaviour of the isotherms. A tentative application of commonly used isotherm models like those of Langmuir or Freundlich was unsuccessful because the fitted constants were found to be dependent on the concentration domain. The commonly used kinetic models (first or second order) are unable to correctly describe the shape of the kinetic curves on the whole time scale and exhibit a dependence on the concentration domain.

The fact that the isotherms apparently depend on the initial concentration and on the contact time demonstrates that the experimental system was not at equilibrium and this was decisive for the development and application of the conceptual model 
presented. So, the term "pseudo-isotherm" is more suitable than "isotherm" and will

380 be used hereafter.

381 The modelling results and the experimental data are represented in Figure 2 for the

382 kinetic study (Figures 2.a and 2.c) and for the pseudo-isotherms (Figures 2.b and

383 2.d). The model represents the experimental data in a satisfactory manner.

384 Table 3 shows the values of the adjusted parameters by molecule. It is important to

385 note that only one set of parameters for each molecule allows the model to correctly

386 predict the overall data obtained in different conditions.

387

388 The relevance of the adjusted values of the parameters was assessed through their 389 physical significance.

390 The constant $\mathrm{K}_{\mathrm{e}}$, having the units of $\mathrm{m}^{3} \mathrm{~m}^{-2}$, is not comparable with other adsorption

391 constant values (in $\mathrm{L} \mathrm{kg}^{-1}$ ) presented in the literature because of the different

392 adsorption models applied and the hypotheses concerning the equilibrium state.

393 The effective diffusion coefficients (shown in Table 3) for the two types of pores

394 considered in the model were calculated using the formula of Eq.14 and Eq.15. The

395 values are reasonable for the type of porosity and diffusion mechanism considered.

396 For reference, the molecular diffusion coefficients in water are $9.5^{\star} 10^{-10} \mathrm{~m}^{2} \mathrm{~s}^{-1}$ and

$3976.6^{*} 10^{-10} \mathrm{~m}^{2} \mathrm{~s}^{-1}$ for toluene and naphthalene respectively.

398 Finally, the $k_{\text {ext }}$ value corresponds to typical values for liquid transfer around solid

399 particles in stirred liquids, which are commonly between $10^{-6}$ and $10^{-4} \mathrm{~m} \mathrm{~s}^{-1}$.

400

401 The adsorption in a non-homogenous porous matrix is a sequential process in terms

402 of mass transfer and sorbate distribution among the different compartments. If, 403 during the first moments, it is essentially the external surface that is occupied by the 
404 sorbate, the prolonged contact time favours a redistribution of the molecules over the

405 different compartments driven by the concentration gradient. This phenomenon 406 depends on the diffusion coefficients and slows down the attainment of an 407 equilibrium state.

408

409 The curves in Figures $3 . a$ and $3 . b$ were obtained by simulation using the 410 experimental conditions of the kinetic study in the case of naphthalene

$411\left(\mathrm{C}_{0}=22 \mathrm{~g} \mathrm{~m}^{-3}, \mathrm{~S} / \mathrm{L}=0.04 \mathrm{~g} \mathrm{~L}^{-1}\right)$ and using the fitted values of the model parameters (as

412 listed in Table 3). For comparison, a simulation was also made with $\mathrm{S} / \mathrm{L}=4 \mathrm{~g} \mathrm{~L}^{-1}$ and is 413 represented by the grey lines in Figure 3.a.

414 Figure 3.b shows the total quantity adsorbed $Q$ (Eq.23) and the distribution of the 415 sorbent among the different compartments of the GAC particles as calculated by the 416 model: on the external surface $\left(\sigma_{\text {ext }} \mathrm{Q}_{\text {ext }}\right)$, adsorbed on macro- and meso-pore 417 surfaces $\left(\sigma_{p} \bar{Q}_{p}\right)$, retained in macro- and meso-pore liquid $\left(\mathrm{V}_{\mathrm{p}} \overline{\mathrm{C}}_{\mathrm{p}}\right)$, adsorbed in 418 micropores $\left(\sigma_{\mathrm{mp}} \overline{\mathrm{Q}}_{\mathrm{mp}}\right)$.

420 Two kinetic domains can be distinguished at different time scales: firstly a short 421 period of several hours corresponding to a massive adsorption on the external 422 surface, followed by a steep decrease in the bulk concentration due to macropore 423 adsorption. A pseudo-equilibrium state is observed after about 100h 424 (for $S / L=0.04 \mathrm{~g} \mathrm{~L}^{-1}$ ) when the bulk concentration seems to be stabilised but, in fact, a 425 slow increase in the micropore adsorption still occurs. A significant evolution of the 426 macroscopic parameters (bulk concentration) would be observed only at very long 427 time periods due to the very slow diffusion in the micropores. The influence of solid to 428 liquid ratio on the macroscopic behaviour of the adsorption process is significant, the 
pseudo-equilibrium state being more rapidly attained for high S/L (grey curves in Fig 3.a). The model used here considers that the different types of pores are

431 independent (parallel), i.e. the micropores and macropores do not communicate 432 inside the porous system but communicate directly with the bulk liquid. This is an

433 "optimistic" model because the concentration gradient for microporous diffusion is at 434 its maximum (in non-equilibrium adsorption, the bulk liquid is always more 435 concentrated than that in the macropores). The simulations show that, even with this 436 optimistic hypothesis, molecules like PAH in aqueous solutions are mostly adsorbed 437 in the macro- and meso-porosity (for short time periods) and thus the use of 438 microporous GAC is not necessary.

Among the adjusted parameters, the adsorption constant, $\mathrm{K}_{\mathrm{e}}$, and the mass transfer coefficient for macro- and meso-pores $k_{o, p}$ (or the effective diffusion coefficient $D_{e}$ ) are the most sensitive. Figure 4.a shows a sensitivity study carried out for the kinetic 443 curve of naphthalene. Each curve was calculated by multiplying the parameters $\mathrm{K}_{\mathrm{e}}$, $444 D_{e}, D_{s}$ and $k_{\text {ext }}$ by 10 , one by one. The sensitivity of a given parameter is not the 445 same over the whole time scale and this result was expected.

446 The effective diffusion coefficient affects the first period when meso- and macro-pore 447 adsorption takes place. An increase in the adsorption coefficient results in a slowing 448 down of the adsorption kinetics (Valderrama et al., 2008b) and, obviously, in another 449 equilibrium (pseudo-equilibrium) state. The least sensitive parameter is the solid 450 diffusion coefficient and this is explained by a low adsorption in the micropores, at 451 least for the time scale studied. The external mass transfer parameter is not sensitive 452 either; $k_{\text {ext }}$ for liquid films in stirred systems takes values between $10^{-4}$ and $10^{-6} \mathrm{~m} \mathrm{~s}^{-1}$ 453 (Roustan, 2003) and, in this range, the simulations are within the experimental data 454 domain. The GAC used in industrial applications has narrow size dispersion so the 
455 particle radius should not be a sensitive parameter for a given GAC type.

456 Calculations made with $2 \mathrm{R}$ and $\mathrm{R} / 2$ gave the same sensitivity results as $k_{\text {ext }}$ (in

457 formula 14 and 15 it is obvious that the diffusion coefficient makes the major 458 contribution to the overall transport).

459

460 The model was then confronted with desorption experiments (naphthalene) in order

461 to validate it and to evaluate its predictive performance. The complex experimental

462 protocol composed of an adsorption step followed by two successive desorption

463 steps was simulated using the previously adjusted parameters. As Figure 4.b shows,

464 the simulation results are in agreement with the experimental values.

\section{Conclusions}

468 The experimental study of the adsorption/desorption process in various operating 469 conditions and the modelling and simulation work lead to the conclusions drawn 470 below.

471 1) The adsorption/desorption of aromatic compounds in aqueous solutions on GAC is

472 a complex process which cannot be represented by simple and usual kinetic models 473 (pseudo-first-order, second order, intraparticle diffusion or Elovich) over a wide range 474 of initial concentrations and time periods. These models are not predictive because 475 the equations and parameters contained in them lack physical meaning.

476 2) Pseudo-equilibrium states were observed on kinetic curves after about twenty 477 hours of contact. Experimental isotherms determined with different initial 478 concentrations and for different contact times clearly show that reaching the 479 equilibrium state requires hundreds of hours. 
3) A multi-compartment dynamic model allowed the deconvolution of the

481 experimentally observed curves and explains the occurrence of many kinetic

482 domains. These kinetic domains are related to the GAC structure and correspond to

483 the different dynamic processes: on the particle surface, in the macro-meso pores

484 and in the micropores. It was expected a priori and then demonstrated by modelling

485 that, at short times, the external surface adsorbs the major part of the solute, then a

486 redistribution of the adsorbed quantity takes place by migration inside the macro-

487 meso pores and then in the micropores, tending towards an equilibrium state in the 488 long term.

489 4) Concerning the structure of the model, a set of four parameters characterising the

490 solute-sorbent interaction (linear adsorption constant and transport parameters) are

491 necessary and cannot be obtained by direct measurements. These parameters are

492 evaluated by fitting the model on a set of experimental data. Once the set of four

493 parameters has been determined, the model becomes predictive for the molecule-

494 GAC pair, being able to simulate the sorption (adsorption-desorption) process in

495 different conditions of concentrations (large range of $\mathrm{C}_{0, \exp }$ ), liquid/solid ratios, contact

496 times, initial conditions, etc. This is what was demonstrated by the successful

497 simulation of successive adsorption-desorption experiments in the case of 498 naphthalene.

499 5) The modelling and simulation results confirm the experimental observations and

500 show that, for short time periods, the major adsorbed quantity is located on the

501 external surface and in the macro-meso pores. This conclusion is important for

502 further process design, for the choice of the GAC according to its porous structure

503 and in relation with the process contact time. 
504 6) The model takes into account the dominant phenomena occurring in the system

505 studied and the specific properties of the adsorbent related to the porous system,

506 being sufficiently complete to describe this kind of system. The principal weakness

507 lies in the parallel pore assumption, the main consequence of which could be a slight

508 overestimate of the microporous adsorption (supposition not verified). However, in

509 the case of the system studied (PAH in aqueous solution adsorbed on GAC), the

510 microporous adsorption is still very low and hardly useful for a real application.

511 Consequently, the model presented is considered well suited to modelling

512 adsorption/desorption processes for aqueous PAH solutions on GAC.

513 7) Besides its predictive character, the model is mathematically simple and easy to

514 solve, and hence it can be easily used in more complex models describing treatment

515 processes and coupled bio-physico-chemical phenomena or it can be used with

516 different adsorption equilibrium laws (non-linear in this case).

\section{Acknowledgements}

519

520 The authors thank Evrard Mengelle and Gérard Cancel for their technical support.

521 This work was partly supported by the research agency of the French government

522 (ANR). Activated carbon characterization was performed in Ecole des Mines Albi, 523 centre RAPSODEE, campus Jarlard, F-81013 Albi, France. 
525

526

527

528

529

530

531

532

533

534

535

536

537

538

539

540

541

542

543

544

545

546

547

548

549

550

551

552

553

554

555

556

557

558

559

560

561

Water Framework Directive 2000. Directive 2000/60/EC of the European Parliament and of Council of 23 October 2000 establishing a framework for community action in the field of water policy. Official Journal of the European Communities, p. 1-72.

Ania, C.O., Cabal, B., Pevida, C., Arenillas, A., Parra, J.B., Rubiera, F., Pis, J.J., 2007. Effects of activated carbon properties on the adsorption of naphthalene from aqueous solutions. Applied Surface Science 253, 5741.

Bouchez, D., Vittorioso, P., Courtial, B., Camilleri, C., 1996. Kanamycin rescue: A simple technique for the recovery of T-DNA flanking sequences. Plant Molecular Biology Reporter 14, 115-123.

Cabal, B., Ania, C.O., Parra, J.B., Pis, J.J., 2009a. Kinetics of naphthalene adsorption on an activated carbon: Comparison between aqueous and organic media. Chemosphere 76, 433-438.

Cabal, B., Budinova, T., Ania, C.O., Tsyntsarski, B., Parra, J.B., Petrova, B., 2009b. Adsorption of naphthalene from aqueous solution on activated carbons obtained from bean pods. Journal of Hazardous Materials 161, 1150-1156.

Cheremisinoff, N.P., Cheremisinoff, P.N., 1993. Carbon adsorption for pollution control.

Chien, S.H., Clayton, W.R., 1980. Application of Elovich Equation to the Kinetics of Phosphate Release and Sorption in Soils. Soil Sci Soc Am J 44, 265-268.

Cooney, D.O., Xi, Z.P., 1994. Activated Carbon Catalyzes Reactions of Phenolics during Liquid-Phase Adsorption. Aiche Journal 40, 361-364.

Cornelissen, G., Gustafsson, Ouml, 2005. Predictions of large variations in biota to sediment accumulation factors due to concentration dependent black carbon adsorption of planar hydrophobic organic compounds; Environmental Toxicology and Chemistry 24, 495-498.

Crittenden, J.C., Hand, D.W., Arora, H., Lykins, B.W., 1987. Design Considerations for Gac Treatment of Organic-Chemicals. Journal American Water Works Association 79, 74-82.

Derylo-Marczewska, A., M. Jaroniec, D. Gelbin and A. Seidel, 1984. Heterogeneity effects in single-solute adsorption from dilute solutions on solids. Chem. Scr 24, 239-246.

Ding, L.P., Bhatia, S.K., Liu, F., 2002. Kinetics of adsorption on activated carbon: application of heterogeneous vacancy solution theory. Chemical Engineering Science, 57, 3909-3928

Do, D.D., Rice, R.G., 1986. Validity of the Parabolic Profile Assumption in Adsorption Studies. Aiche Journal 32, 149-154.

Douben, 2003. PAHs: An Ecotoxicological Perspective. Ecological and Environmental Toxicology Series. P.E.T. Douben. 
Gleuckauf, J.I.C.a.E., 1947. The influence of incomplete equilibrium on the front boundary of chromatograms and the effectiveness of separation. J Chem Soc, 13151321.

Goto, M., Smith, J.M., Mccoy, B.J., 1990. Parabolic Profile Approximation (Linear Driving-Force Model) for Chemical-Reactions. Chemical Engineering Science 45, 443448.

Huang, C.W., Hung, Y.T., Lo, H.H., 1988. Contact Oxidation Process Followed by Activated Carbon Adsorption for Textile Waste-Water Treatment. Acta Hydrochimica Et Hydrobiologica 16, 593-605.

Jonker, M.T.O., Koelmans, A.A., 2002. Extraction of polycyclic aromatic hydrocarbons from soot and sediment: Solvent evaluation and implications for sorption mechanism. Environmental Science \& Technology 36, 4107-4113.

Lagergren, 1898. Zur theorie der sogenannten adsorption gelöster stoffe. K. Sven 24, 139.

Liu, Y., Shen, L., 2008. From Langmuir Kinetics to First- and Second-Order Rate Equations for Adsorption. Langmuir 24, 11625.

Pikaar, I., Koelmans, A.A., van Noort, P.C.M., 2006. Sorption of organic compounds to activated carbons. Evaluation of isotherm models. Chemosphere 65, 2343-2351.

Roustan, M., 2003. Transfert gaz-liquide dans les procédés de traitement des eaux et des 581 effluents gazeux, Lavoisier, 798p.

Seidel, A., Tzscheutschler, E., Radeke, K.-H., Gelbin, D., 1985. Adsorption equilibria of aqueous phenol and indol solutions on activated carbons. Chemical Engineering Science 40, 215.

Seredych, M.M., Gun'ko, V.M., Gierak, A., 2005. Structural and energetic heterogeneities and adsorptive properties of synthetic carbon adsorbents. Applied Surface Science 242, 154.

Srivastava, S.K., Tyagi, R., 1995. Competitive adsorption of substituted phenols by activated carbon developed from the fertilizer waste slurry. Water Research 29, 483.

590 Summers, R.S., Roberts, P.V., 1988. Activated Carbon Adsorption of Humic Science 122, 367-381.

Valderrama, C., Cortina, J.L., Farran, A., Gamisans, X., Heras, F.X.D.L., 2008a. Kinetic study of acid red "dye" removal by activated carbon and hyper-cross-linked polymeric sorbents Macronet Hypersol MN200 and MN300. Reactive \& Functional

597 Valderrama, C., Cortina, J.L., Farran, A., Gamisans, X., Lao, C., 2007. Kinetics of 598 sorption of polyaromatic hydrocarbons onto granular activated carbon and Macronet 599 hyper-cross-linked polymers (MN200). Journal of Colloid and Interface Science 310, 35600 46. 
601 Valderrama, C., Gamisans, X., de las Heras, X., Farran, A., Cortina, J.L., 2008b.

602 Sorption kinetics of polycyclic aromatic hydrocarbons removal using granular activated 603 carbon: Intraparticle diffusion coefficients. Journal of Hazardous Materials 157, 386-

604396.

605 Vinod, V.P., Anirudhan, T.S., 2003. Adsorption Behaviour of Basic Dyes on the Humic 606 Acid Immobilized Pillared Clay. Water, Air, \& Soil Pollution 150, 193.

607 Weber, W.J.J., J.C. Morris, 1963. Kinetics of adsorption on carbon from solution. J.

608 Sanit. Eng. Div. 89, 31-60.

609 WHO, 2006. Guidelines for Drinking water Quality. World Health Organization Press, 610 Switzerland.

611 Williams, P.T., 1990. Sampling and Analysis of Polycyclic Aromatic-Compounds from 612 Combustions Systems - a Review. Journal of the Institute of Energy 63, 22-30.

613 Wu, F.C., Tseng, R.L., Huang,S.C., Juang, R.S., 2009. Characteristics of pseudo-second614 order kinetic model for liquid-phase adsorption: A mini-review. Chemical Engineering 615 Journal

616 Zimmerman, J.R., Ghosh, U., Millward, R.N., Bridges, T.S., Luthy, R.G., 2004. Addition 617 of Carbon Sorbents to Reduce PCB and PAH Bioavailability in Marine Sediments:

618 Physicochemical Tests. Environmental Science \& Technology 38, 5458.

619 


\section{Figure captions}

620

621 Figure 1.a: Scanning electron micrographs of the activated carbon PICAS35; b) scheme of a

622 GAC particle

623

624 Figure 2.a: Adsorption kinetics of toluene at $25^{\circ} \mathrm{C},(\bullet) \mathrm{C}_{0, \exp }=5 \mathrm{~g} \mathrm{~m}^{-3}(\Delta) \mathrm{C}_{0, \exp }=13 \mathrm{~g} \mathrm{~m}^{-3}$

625 Figure 2.b: Adsorption pseudo-isotherms of toluene at $25^{\circ} \mathrm{C}(\bullet) \mathrm{C}_{0, \exp }=21 \mathrm{~g} \mathrm{~m}^{-3} /$ contact

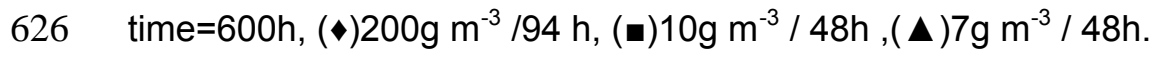

627 Figure 2.c: Adsorption kinetics of naphthalene at $25^{\circ} \mathrm{C},(\boldsymbol{\Delta}) \mathrm{C}_{0, \exp }=20 \mathrm{~g} \mathrm{~m}^{-3}$.

628 Figure 2.d: Adsorption pseudo-isotherms of naphthalene at $25^{\circ} \mathrm{C}(\bullet) \mathrm{C}_{0, \exp }=6 \mathrm{~g} \mathrm{~m}^{-3} /$ contact

629 time=48h, $(\boldsymbol{\Delta}) 30 \mathrm{~g} \mathrm{~m}^{-3} / 144 \mathrm{~h}$.

630

631 Figure 3.a: Simulation of adsorption behaviour: (a) Naphthalene concentration $\left(\mathrm{g} \mathrm{m}^{-3}\right)$ in

632 liquid compartments with two different Solid/Liquid ratios: $S / L=0.04 \mathrm{~g} \mathrm{~L}^{-1}$ (black lines) and

$633 \mathrm{~S} / \mathrm{L}=4 \mathrm{~g} \mathrm{~L}^{-1}$ (grey lines) with $\mathrm{C}_{0}=22 \mathrm{~g} \mathrm{~m}^{-3}$.

634 Figure 3.b: Naphthalene distribution between the particle compartments with $\mathrm{C}_{0}=22 \mathrm{~g} \mathrm{~m}^{-3}$

635 and $\mathrm{S} / \mathrm{L}=0.04 \mathrm{~g} \mathrm{~L}^{-1}$.

636

637 Figure 4.a: Sensitivity analysis on adsorption kinetics of naphthalene $\left(\mathrm{C}_{0, \exp }=20 \mathrm{~g} \mathrm{~m}^{-3}\right)$.

638 Experimental data $(\triangleleft)$ and simulated data (black line), effect of $K_{e}, D_{e}, D_{s}$ and $k_{\text {ext }}$.

639 Figure 4.b: Pseudo-isotherms of adsorption and desorption of naphthalene at $25^{\circ} \mathrm{C}(\bullet)$

640 adsorption experimental data $\mathrm{C}_{0, \exp }=6 \mathrm{~g} \mathrm{~m}^{-3}$ /contact time $=48 \mathrm{~h}$; (४)first desorption; ( $\square$ )second

641 desorption; simulated data are represented in line.

642 
642

643

644

645

646

647

648

649

650

\section{Table captions}

Table 1: Model variables

Table 2: Parameters available from experimental data and measurements

Table 3: Parameters estimated by model fitting procedure and estimated diffusion coefficients 
650
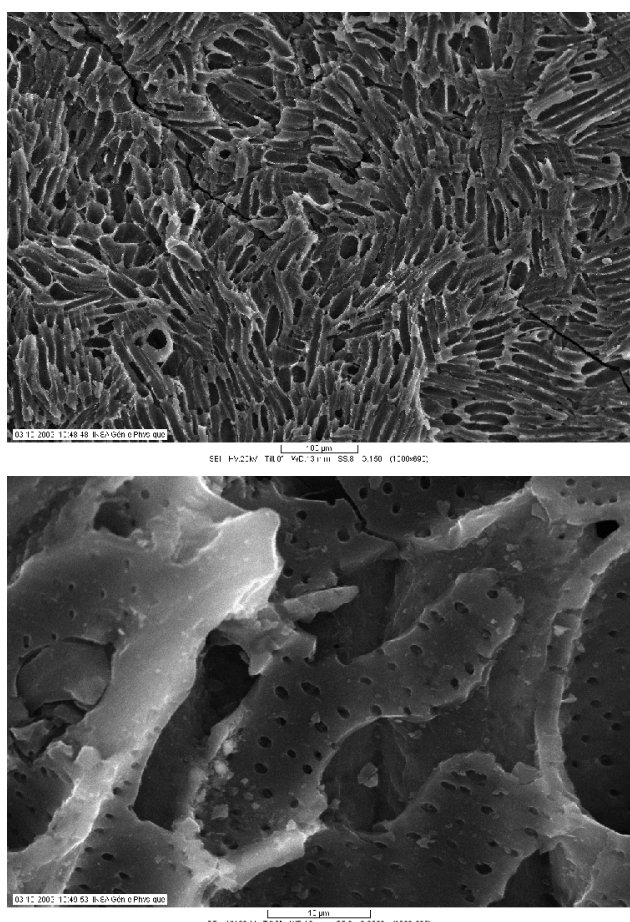

1.a

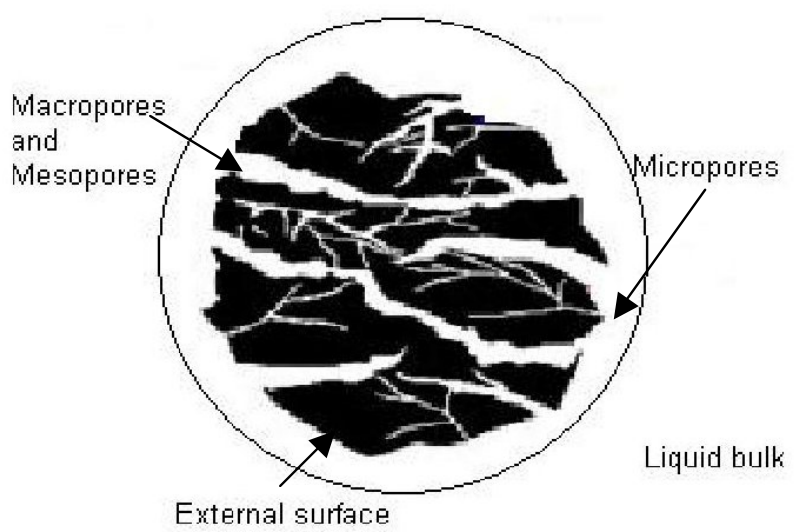

1.b

651 Figure 1 

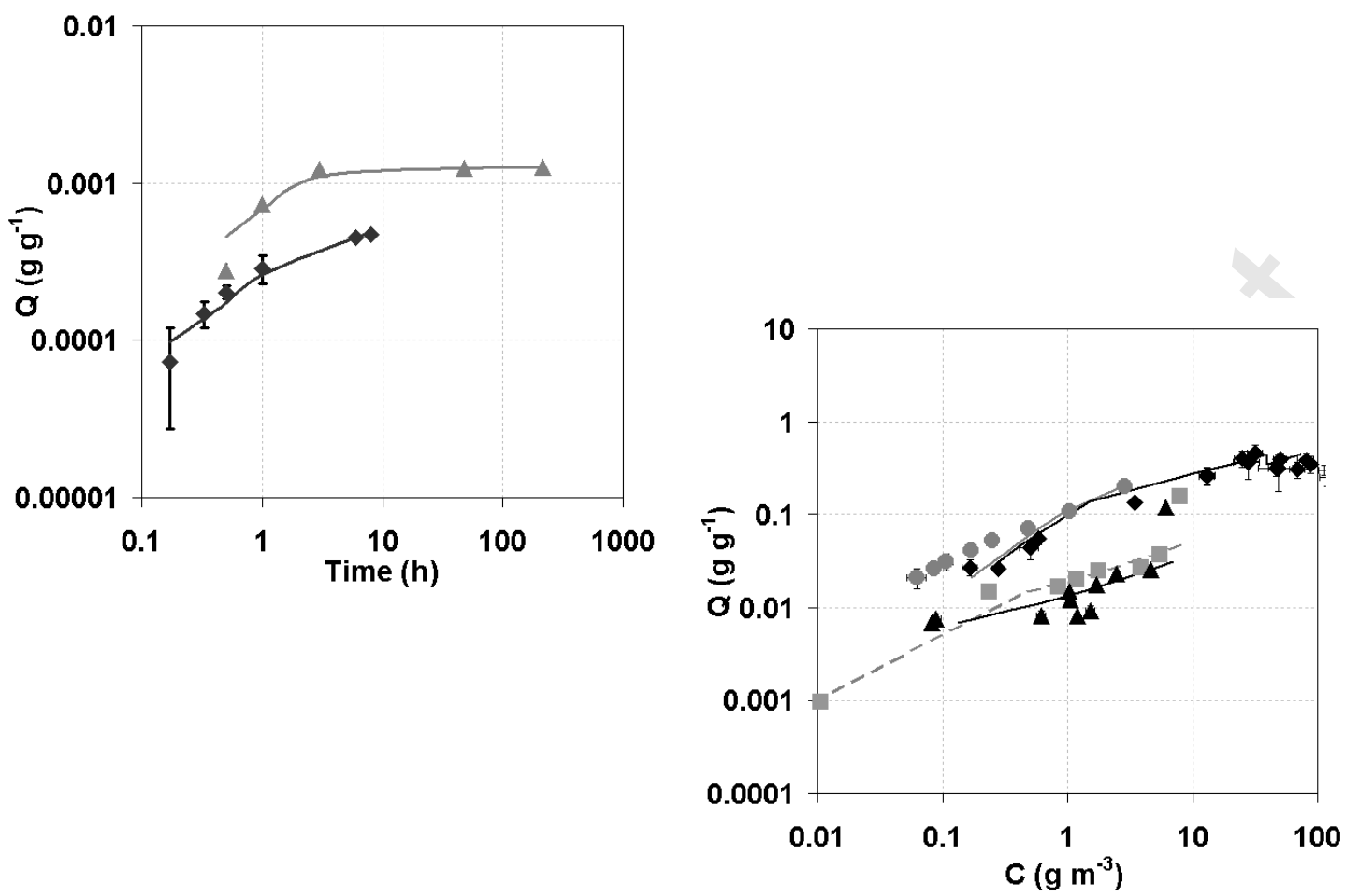

$2 . a$

$2 . b$
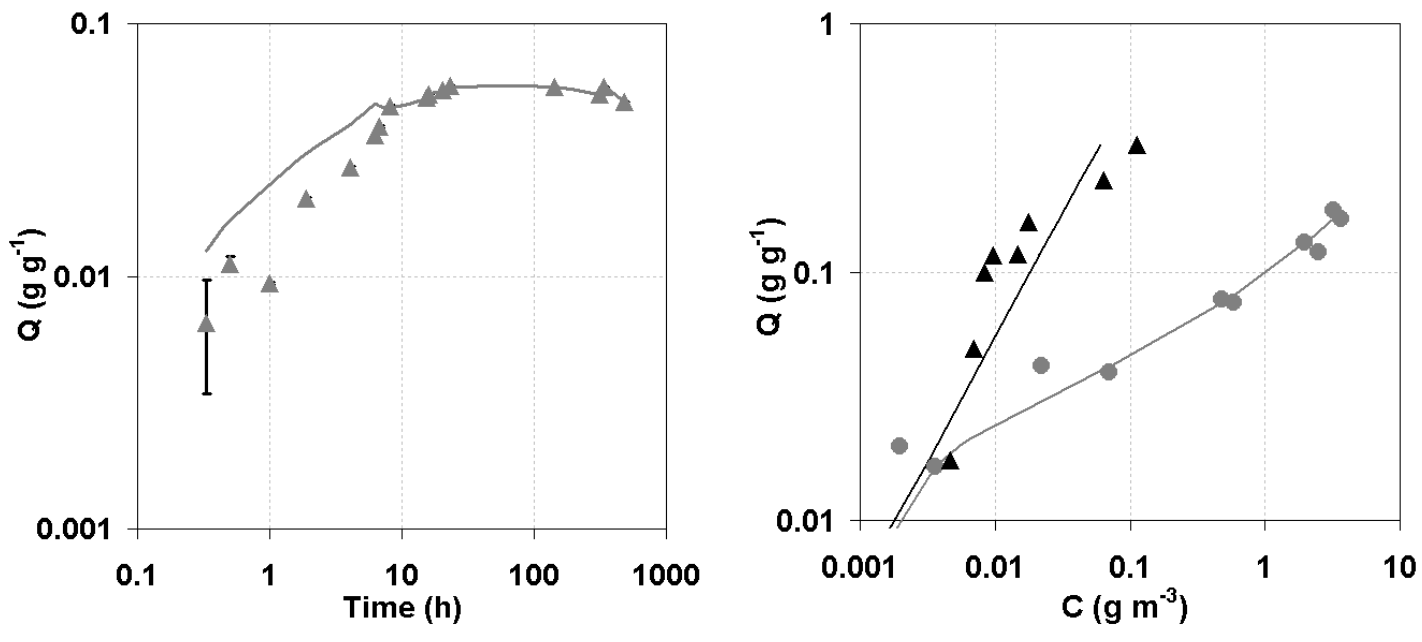

2.c

$2 . d$ 
$652 \quad$ Figure 2

653 
653

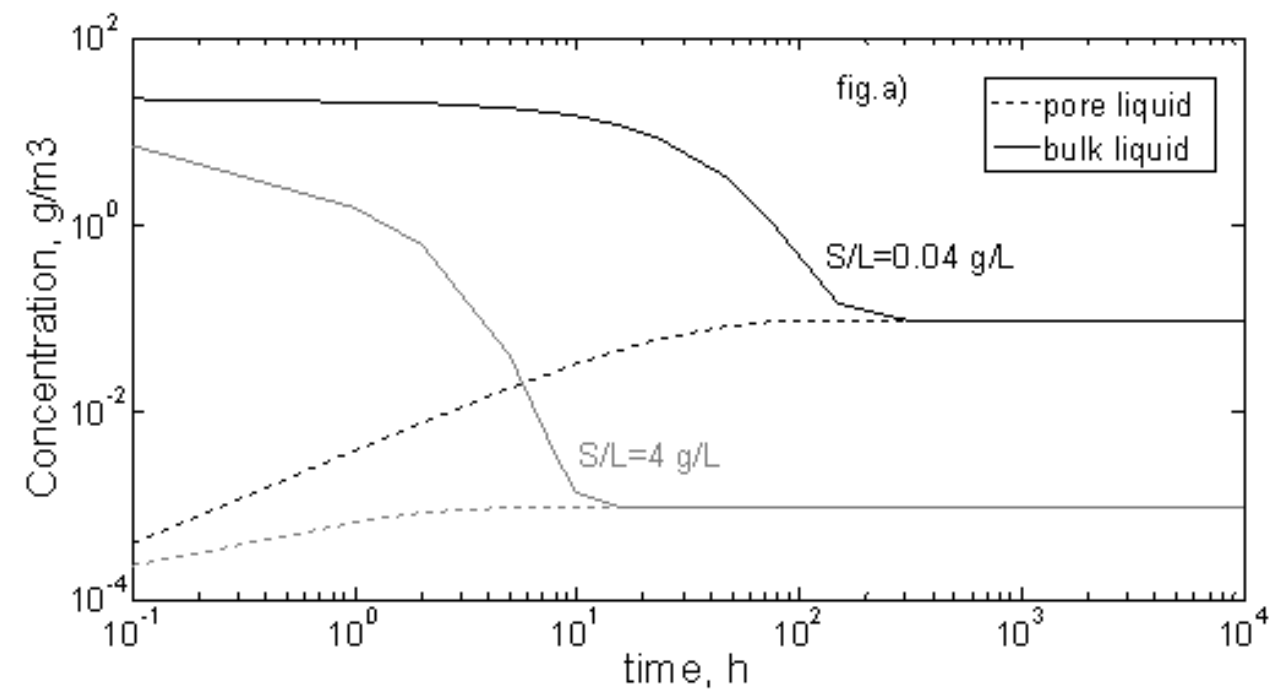

654

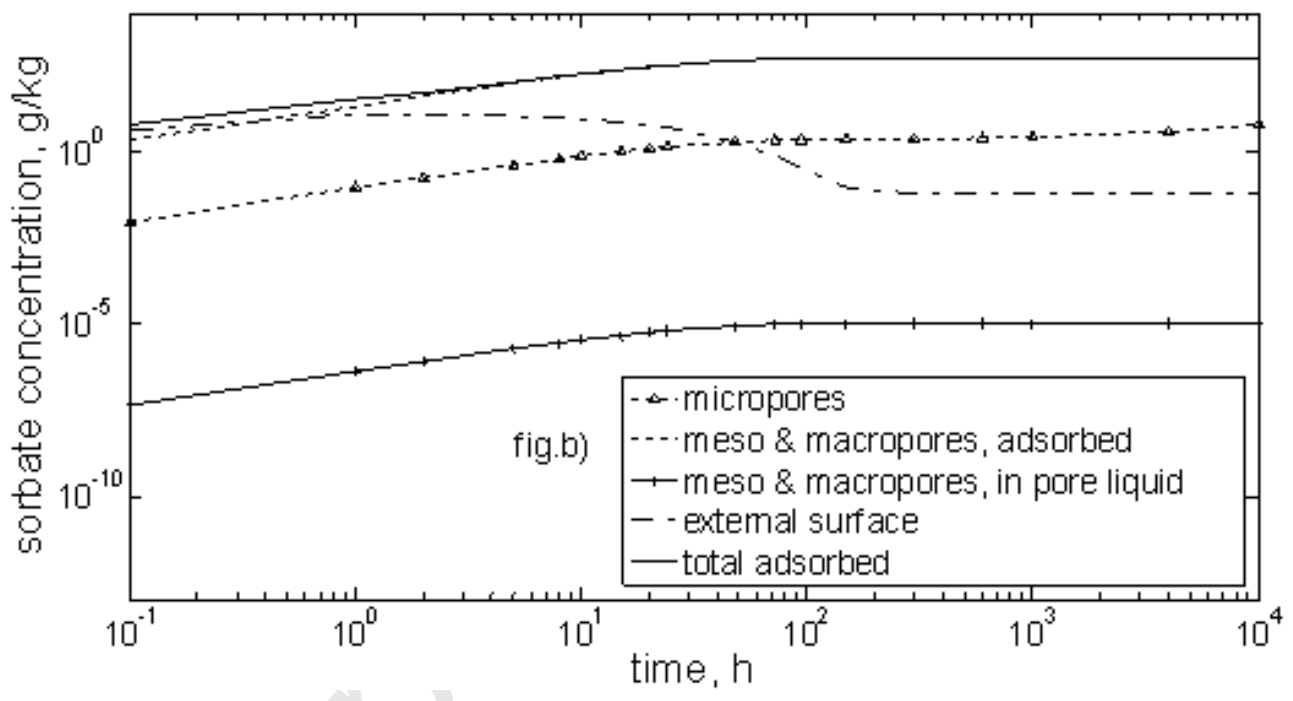

655 Figure 3.

656 
656
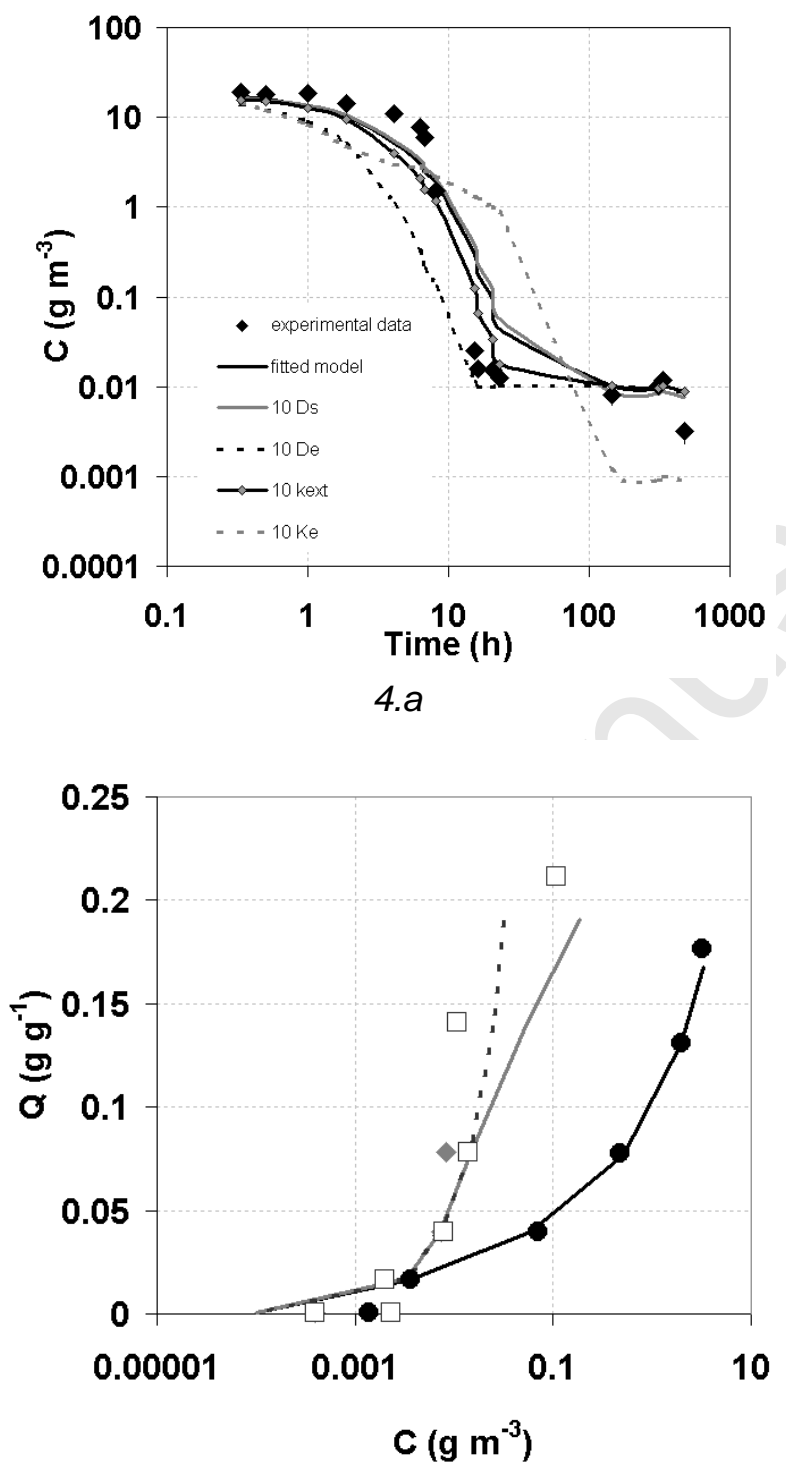

4.b

657 Figure 4

658 
Table 1: Model variables

\begin{tabular}{|c|c|c|}
\hline Variable & Description & Unit \\
\hline$C$ & Concentration in the bulk liquid & $\mathrm{g} \mathrm{m}^{-3}$ \\
\hline$C_{e x t}^{e}$ & $\begin{array}{l}\text { Equilibrium concentration close to the } \\
\text { external surface }\end{array}$ & $\mathrm{g} \mathrm{m}^{-3}$ \\
\hline$C_{p}$ & $\begin{array}{l}\text { Concentration in the mesopores and } \\
\text { macropores }\end{array}$ & $\mathrm{g} \mathrm{m}^{-3}$ \\
\hline $\bar{C}_{p}$ & $\begin{array}{l}\text { Mean concentration in the mesopores and } \\
\text { macropores }\end{array}$ & $\mathrm{g} \mathrm{m}^{-3}$ \\
\hline$C_{m p}^{e}$ & $\begin{array}{l}\text { Equilibrium concentration in the liquid } \\
\text { phase at the micropore inlet }\end{array}$ & $\mathrm{g} \mathrm{m}^{-3}$ \\
\hline $\bar{C}_{m p}^{e}$ & $\begin{array}{l}\text { Equilibrium mean concentration in the } \\
\text { liquid phase at the micropore inlet }\end{array}$ & $\mathrm{g} \mathrm{m}^{-3}$ \\
\hline$Q$ & Total quantity adsorbed & $\mathrm{g} \mathrm{g}^{-1}$ \\
\hline$Q_{e x t}$ & $\begin{array}{l}\text { Quantity adsorbed on the particle external } \\
\text { surface }\end{array}$ & $g^{-2}$ \\
\hline$Q_{p}$ & $\begin{array}{l}\text { Quantity adsorbed in the mesopores and } \\
\text { macropores }\end{array}$ & $\mathrm{g} \mathrm{m}^{-2}$ \\
\hline $\bar{Q}_{p}$ & $\begin{array}{l}\text { Mean quantity adsorbed in the mesopores } \\
\text { and macropores }\end{array}$ & $\mathrm{g} \mathrm{m}^{-2}$ \\
\hline$Q_{m p}$ & Quantity adsorbed in the micropores & $\mathrm{g} \mathrm{m}^{-2}$ \\
\hline $\bar{Q}_{m p}$ & Mean content in the micropores & $\mathrm{g} \mathrm{m}^{-2}$ \\
\hline$r$ & Radial direction & $\mathrm{m}$ \\
\hline 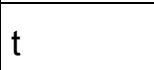 & Time & $\mathrm{s}$ \\
\hline
\end{tabular}

659 
Table 2: Parameters available from experimental data and measurements

\begin{tabular}{|c|c|c|c|}
\hline Parameter & Description & Unit & $\begin{array}{l}\text { Experimental value or } \\
\text { estimation }\end{array}$ \\
\hline$a_{s}$ & Specific surface area of GAC particles & $m^{2} m^{-3}$ & $a_{s}=f_{a}(3 / R) ; a_{s}=39340$ \\
\hline$f_{a}$ & Shape factor & - & $\begin{array}{l}\text { 4.3; estimated by microscope } \\
\text { imaging (Figure 1.a) }\end{array}$ \\
\hline$C_{0, \exp }$ & $\begin{array}{l}\text { Concentration of the pollutant solution } \\
\text { used for adsorption (desorption) } \\
\text { experiments }\end{array}$ & $\mathrm{g} \mathrm{m}^{-3}$ & Different experimental values \\
\hline $\mathrm{C}_{\exp }$ & $\begin{array}{l}\text { Final concentration in an experimental } \\
\text { sample }\end{array}$ & $\mathrm{g} \mathrm{m}^{-3}$ & Different experimental values \\
\hline V & $\begin{array}{l}\text { Volume of liquid in the experimental } \\
\text { sample }\end{array}$ & $\mathrm{m}^{3}$ & Different experimental values \\
\hline$R$ & Particle mean radius & $\mathrm{m}$ & $3.2510^{-4}$ (manufacturer data) \\
\hline S & GAC mass in the experiments & $g$ & Different experimental values \\
\hline$V_{p}$ & $\begin{array}{l}\text { Volume of mesopores and } \\
\text { macropores }\end{array}$ & $\mathrm{m}^{3} \mathrm{~g}^{-1}$ & $1.110^{-7}$ (BET evaluation) \\
\hline$\rho$ & GAC particle density & $\mathrm{g} \mathrm{m}^{-3}$ & 420000 (manufacturer's data) \\
\hline$\varepsilon$ & Bulk liquid volume fraction & & $\varepsilon=\frac{\mathrm{V}}{(\mathrm{V}+\mathrm{S} / \rho)}$ \\
\hline$\varepsilon_{p}$ & Mesopore- and macropore porosity & & $\varepsilon_{\mathrm{p}}=\rho \mathrm{V}_{\mathrm{p}}$ \\
\hline$\sigma_{p}$ & $\begin{array}{l}\text { Mesopore and macropore specific } \\
\text { surface area }\end{array}$ & $\mathrm{m}^{2} \mathrm{~g}^{-1}$ & 394 (BET evaluation) \\
\hline$\sigma_{m p}$ & Micropore specific surface area & $\mathrm{m}^{2} \mathrm{~g}^{-1}$ & 1576.6 (BET evaluation) \\
\hline$\sigma_{\text {ext }}$ & $\begin{array}{l}\text { External surface specific area } \\
\text { available for adsorption }\end{array}$ & $\mathrm{m}^{2} \mathrm{~g}^{-1}$ & $\sigma_{\text {ext }}=0.5\left(a_{\mathrm{s}} / \rho\right)$ \\
\hline
\end{tabular}

660 
660

661

662

663
Table 3: Parameters estimated by model fitting procedure and estimated diffusion coefficients

\begin{tabular}{|c|l|c|c|c|}
\hline Parameter & \multicolumn{1}{|c|}{ Description } & Unit & Toluene & Naphthalene \\
\hline $\mathrm{K}_{\mathrm{e}}$ & Adsorption equilibrium constant & $\mathrm{m}$ & $2.310^{-4}$ & $1.3810^{-2}$ \\
\hline $\mathrm{k}_{\mathrm{o}, \mathrm{p}}$ & $\begin{array}{l}\text { Mesopore/macropore overall mass } \\
\text { transfer coefficient }\end{array}$ & $\mathrm{m} \mathrm{s}^{-1}$ & $1.910^{-1}$ & $2.210^{-6}$ \\
\hline $\mathrm{k}_{\mathrm{o}, \mathrm{mp}}$ & $\begin{array}{l}\text { Micropore overall mass transfer } \\
\text { coefficient }\end{array}$ & $\mathrm{m} \mathrm{s}^{-1}$ & $1.910^{-8}$ & $1.910^{-8}$ \\
\hline $\mathrm{k}_{\mathrm{ext}}$ & External mass transfer coefficient & $\mathrm{m} \mathrm{s}^{-1}$ & $1.010^{-5}$ & $7.010^{-6}$ \\
\hline $\mathrm{D}_{\mathrm{e}}$ & $\begin{array}{l}\text { Effective mesopore/macropore pore } \\
\text { diffusion coefficient }\end{array}$ & $\mathrm{m}^{2} \mathrm{~s}^{-1}$ & $1.310^{-11}$ & $2.110^{-10}$ \\
\hline $\mathrm{D}_{\mathrm{s}}$ & Effective surface diffusion coefficient & $\mathrm{m}^{2} \mathrm{~s}^{-1}$ & $1.210^{-12}$ & $1.210^{-12}$ \\
\hline
\end{tabular}

